\title{
SENSORIAMENTO REMOTO E GEOPROCESSAMENTO APLICADOS AO ZONEAMENTO GEOAMBIENTAL: Bacia Hidrográfica do Açude Camará - PB
}

\author{
Msc. Sâmara Rachel Ribeiro da Silva \\ Empresa Brasileira de Pesquisas Agropecuárias - EMBRAPA/CNPM \\ Av. Soldado Passarinho, 303 - Fazenda Chapadão, CEP: 13070-115 - Campinas (SP), Brasil \\ Tel. (+ 55 19) 32116200 - samara@cnpm.embrapa.br \\ Prof. Dr. Iêde de Brito Chaves \\ iedebchaves@hotmail.com \\ Prof. Dr. José Jakson Amâncio Alves \\ jaksonamancio@uepb.edu.br
}

\begin{abstract}
RESUMO
A diversidade de paisagens da bacia hidrográfica da barragem Camará, principalmente no que se refere às formas de relevo, de solos e de sistemas de produção, induziu a realização deste zoneamento geoambiental. Sua importância reside nas preocupações com a conservação do meio ambiente e com o desenvolvimento sócio-econômico e a preservação dos recursos naturais na área em busca do desenvolvimento sustentável. Este trabalho teve como objetivo criar um banco de dados atualizado e, com o zoneamento geoambiental, realizar uma análise simplificada dos atributos fisiográficos, solo, clima, relevo e uso da terra, separando e descrevendo unidades da paisagem, suas potencialidades e limitações. Foram utilizadas nesta pesquisa imagem do satélite CBERS e técnicas de geoprocessamento a partir do programa SPRING, bases para os trabalhos descritivos em campo. A partir das informações de solo, relevo e uso da terra foram descritas as áreas susceptíveis a degradação ambiental.
\end{abstract}

Palavras-chave: SPRING. Uso da Terra. Vulnerabilidade Ambiental.

\begin{abstract}
The diversity of landscapes at the Camará dam hydrographic basin, especially in terms of landforms, soils and production systems, has lead to the elaboration of this geoenvironmental zoning. Its importance is reflected in concerns about environmental conservation, socioeconomic development, and preservation of the area's natural resources in pursuit of sustainable development. This work aimed at creating an updated database and at carrying out a simplified analysis of physiographic attributes, soil, climate, topography and land use by means of geoenvironmental zoning for separating and describing landscape units, their potential and their limitations. This research used a CBERS satellite image and geoprocessing (GIS) techniques from the SPRING program, which formed the groundwork for the descriptive field studies. The information obtained for soil, topography and land use was used for the description of areas prone to environmental degradation. The results obtained for the hydrographic basin led to its division into 19 geoenvironmental units.
\end{abstract}

Key words: SPRING. Land Use. Environmental Vulnerability.

\section{RESUMEN}

La diversidad de paisajes en la cuenca de la presa de Cámara, sobre todo en relación con la forma del relieve, el suelo y en la producción, inducida por la realización de la zonificación geoambiental. Su importancia radica en su preocupación por la conservación del medio ambiente y el desarrollo socio-económico y la preservación de los recursos naturales en la zona en búsqueda del desarrollo sostenible. Este estudio tuvo como objetivo crear una base de datos actualizada y con la zonificación geoambiental, realizar un breve análisis de las características fisiográficas, el suelo, el clima, la topografía y el uso de la tierra, la separación y la descripción de las unidades de paisaje, sus fortalezas y limitaciones. Se utilizaron en esta imagen CBERS investigación y técnicas de SIG, SPRING del programa, bases para el trabajo descriptivo en el campo. De la información de suelo, topografía y el uso de la tierra se describieron las zonas propensas a la degradación del medio ambiente. Los resultados obtenidos permitieron en la cuenca dividirlo en 19 unidades ambientales.

Palabras clave: SPRING. Uso De La Tierra. La Vulnerabilidad Ambiental.

\section{INTRODUÇÃO}

No intuito de contribuir com a discussão de propostas de ações para desenvolvimento rural sustentado e para gestão ambiental da bacia Camará, com este zoneamento geoambiental pretende-se oferecer uma análise simplificada dos atributos fisiográficos solo, clima, relevo e uso da terra, 
separando e descrevendo as 19 unidades da paisagem, suas potencialidades e limitações, bases para o planejamento conservacionista.

Rodriguez (2004) considera seis fatores geoambientais na formação da paisagem: geológicos, climatológicos, geomorfológicos, hídricos, edáficos e bióticos, os quais permitem a integração destes aspectos, espacializados numa única Unidade Geoambiental, constituindo-se como uma célula básica de planejamento. A realização de um Zoneamento Geoambiental corresponde a um diagnóstico físico-biótico, cujo objetivo é individualizar zonas do terreno com comportamento similar, para orientar as diretrizes de planejamento e possibilitar a elaboração de prognósticos. Este termo foi oficialmente conceituado no Brasil, pelo decreto $n^{\circ} 5.300$ de 7 de Dezembro de 2004, Lei no 7.661, que regulamenta a Lei de 16 de maio de 1988 e institui o Plano Nacional de Gerenciamento Costeiro - PNGC, onde diz que "Unidade Geoambiental é a porção do território com elevado grau de similaridade entre as características físicas e bióticas, podendo abranger diversos tipos de ecossistemas com interações funcionais e forte interdependência".

Neste sentido, as bacias hidrográficas por possuírem um caráter integrador das dinâmicas ocorridas nas unidades geoambientais, revela-se como excelentes áreas de estudo para o planejamento. Para Rocha (1997) a bacia hidrográfica como unidade geoambiental de estudo pode ser definida, do ponto de vista hidrológico, como território que apresenta uma rede de drenagem comum e delimitada pelos divisores de águas superficiais e subterrâneas, constitui-se um importante indicador das alterações ocorridas na composição da paisagem, seja por mudanças na sua estruturação, forma, ganho ou perda de canais, decorrentes da intensificação do processo erosivo.

A relação entre as técnicas do sensoriamento remoto e os indicadores biofísicos pode ser valiosa para estudos de diagnose e monitoramento, principalmente em habitats vulneráveis e de grande importância na utilização de classificação de solos, uso da terra, levantamento dos recursos naturais e monitoramento do meio ambiente (NOVO, 1988; FREITAS et al., 2005). Esta relação técnica e conceitual do desenvolvimento das ferramentas do geoprocessamento resultou no desenvolvimento de uma enorme variedade de métodos de processamento de dados geográficos. Essas técnicas no Brasil são chamadas de Geoprocessamento (Câmara \& Medeiros, 1996) e nos EUA, de Geomática (Oestensen, 1995), que se utiliza de técnicas matemáticas e computacionais para o tratamento de informações geográficas, a exemplo de imagens de satélites, que podem ser utilizadas em diversas áreas.

Dentre os estudos de análise ambiental, os esforços do Instituto Nacional de Pesquisas Espaciais (INPE), entidade vinculada ao Ministério da Ciência e Tecnologia, se destaca na criação e desenvolvimento do SPRING (Sistema de Processamento de Informações Georreferenciadas) e do SGI (Sistema Geográfico de Informação) (Câmara \& Medeiros, 1996; Câmara et al., 1996), com o objetivo de tratamento computacional de dados geográficos.

Alguns autores vêm ressaltando, a importância do uso de SIGs como ferramentas de análises de sistemas (Ostensen, 1995; Câmara et al., 1996; Câmara \& Medeiros, 1996), diagnóstico do meio físico (Silva et al., 1999; Carvalho Junior, 2003; Duarte, 2003; Faria Filho \& Araújo, 2003; Lacerda, 2003; Lima, 2003; Pedra et al., 2005; Pinto et al., 2005; Rocha, 2005), modelagem (Molenaar, 1996) e impactos (Alves et al., 2000; Schäfer et al., 2004; Trancoso et al., 2005) de bacias hidrográficas, colocando sempre sua importância na integração e visualização de dados, gerência de novas informações, como um sistema de suporte para a tomada de decisão.

\section{MATERIAL E MÉTODOS}

Áreas de estudo

A bacia hidrográfica Camará está situada entre as latitudes de $7^{\circ} 5^{\prime} 5^{\prime \prime}$ e $6^{\circ} 56^{\prime} 53$ " Sul e longitudes de $35^{\circ} 53^{\prime} 47^{\prime \prime}$ e $35^{\circ} 42^{\prime}$ '53" Oeste, e distancia-se aproximadamente $152 \mathrm{~km}$ da capital paraibana, João Pessoa, ocupando uma área de aproximadamente $104 \mathrm{Km} 2$. Abrange parte das 
terras dos municípios de Esperança (a noroeste da bacia - NO), São Sebastião de Lagoa de Roça (SW) e Remígio (N), pertencentes à microrregião do Agreste da Borborema e Alagoa Nova (S) e Areia (NE) localizadas na microrregião do Brejo Paraibano. Na figura 1 observa-se a localização da bacia hidrográfica do açude Camará - PB.

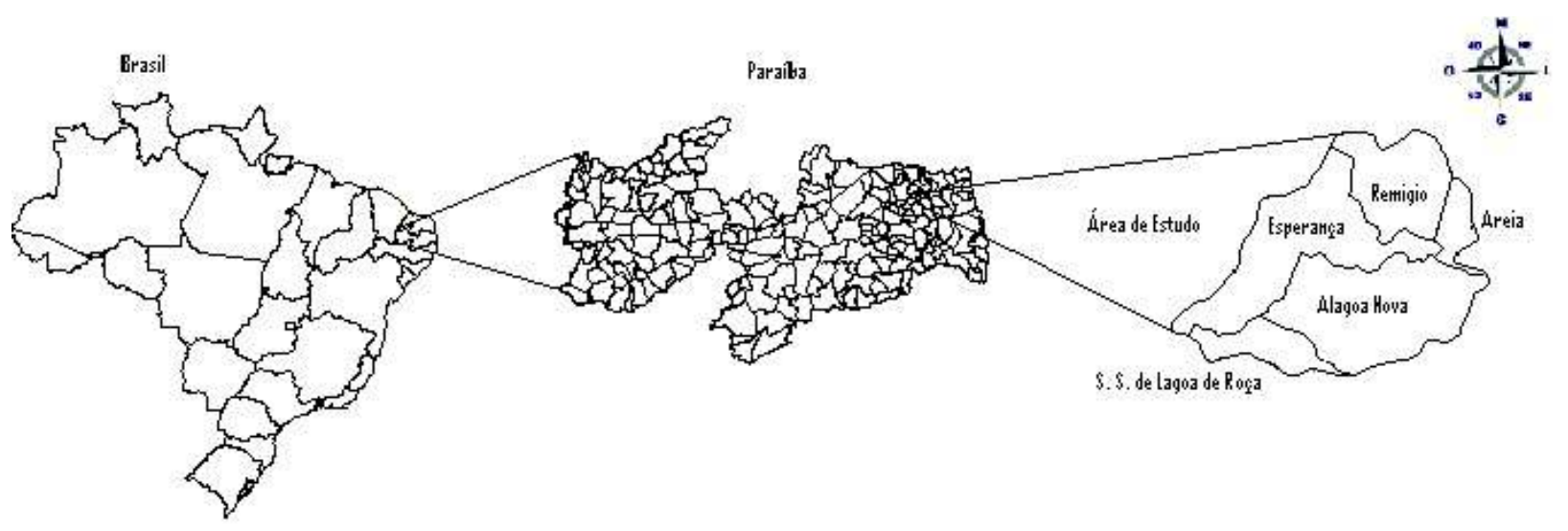

Figura 1. Mapa de localização da bacia hidrográfica do açude Camará/PB e frações territoriais dos municípios contribuintes.

\section{a) Etapas metodológicas}

Foram utilizados nesse estudo os procedimentos para o inventário do meio físico propostos por Lepsch (1991) e Ramalho Filho \& Beek (1994), que têm como base a fundamentação que norteia a distribuição dos solos na paisagem, ou seja, a separação de ambientes onde a interação dos fatores de formação dos solos (rocha, clima, relevo, organismos e tempo) guarda certa semelhança (EMBRAPA, 1995).

A base pedológica de referência neste estudo foi o "Levantamento Exploratório - Reconhecimento de Solos do Estado da Paraíba (BRASIL, 1972)" e o "Levantamento de Solos do Zoneamento Agropecuário da Paraíba, escala 1:200.000 (ELC, 1978)”, onde a área de estudo está representada por unidades de mapeamento, constituída de associações e inclusões de classes de solos, as quais serviram de referência às descrições de campo, para que com o uso do SPRING fosse confeccionado o mapa semidetalhado (escala 1:85.000) de solos da bacia hidrográfica do açude Camará.

O levantamento em campo foi de fundamental importância, pois, percorreu-se um número relevante de estradas e caminhos, que serviram para identificar efetivamente os tipos de solos e de relevo que ocorrem em cada área (ou mancha) individualizada na digitalização automática da imagem, bem como, na obtenção de informações quanto às formas de uso atual e potencial, e por fim, identificar os processos de degradação e/ou erosão das terras. Foram anotados 250 pontos de observações dentro da bacia hidrográfica, à medida que se percorreram as estradas e caminhos as observações foram sendo registradas em fichas para elaboração de relatórios de viagem.

Concluída as etapas de observações e conclusões decorrentes do trabalho em campo foi utilizado o método de extrapolação, fundamentado nas correlações entre relevo, vegetação, uso da terra, hidrografia, etc., dando origem ao mapa de solos na escala de 1:85.000. Na subdivisão das classes e classificação dos solos foram adotados os mesmos critérios do Sistema Brasileiro de Classificação de Solos (EMBRAPA, 1999).

Para o mapa de unidades de paisagem foram digitalizados em tela o mapa base e o mapa classificado de uso da terra, onde se realizou a digitalização, poligonalização e edição no SPRING, e separadas as classes com o auxílio de trabalho de campo e pontos georreferenciados com o GPS. As unidades de paisagem foram separadas utilizando-se dos parâmetros propostos por uma visão geossistêmica, onde se utilizou a observação e descrição do tipo de uso da terra, de solo e de relevo, este último utilizado com cinco classes de descrição (relevo plano, suave ondulado, fortemente ondulado a montanhoso).

Mercator - volume 9, número 20, 2010: set./dez. 
Para avaliar a vulnerabilidade das unidades geoambientais mapeadas na bacia hidrográfica. Foram utilizados os atributos da terra apresentados no Quadro 1, a estes, foram designados valores (índices numéricos) para expressar as características das terras determinantes da suscetibilidade de degradação, tais como: declive, profundidade efetiva, intensidade do uso da terra e densidade populacional, expressa pela distribuição do tamanho das propriedades rurais.

Quadro 1- Fatores utilizados no Índice de Vulnerabilidade Ambiental - IVA

\begin{tabular}{|c|c|c|c|c|}
\hline Índice & Classes de Relevo & Profundidade efetiva & Uso da Terra & Densidade Populacional \\
\hline 1 & $\begin{array}{l}\text { Plano } \\
(0-3 \%)\end{array}$ & $\begin{array}{l}\text { Muito Profundo } \\
\qquad(>2 \mathrm{~m})\end{array}$ & Mata & $\begin{array}{l}\text { Muito Baixa } \\
\text { (> } 50 \text { ha) }\end{array}$ \\
\hline 2 & $\begin{array}{l}\text { Suave Ondulado } \\
\qquad(3-8 \%)\end{array}$ & $\begin{array}{l}\text { Profundo } \\
\text { (1 à } 2 \mathrm{~m})\end{array}$ & Capoeira ou Culturas Perenes & $\begin{array}{l}\text { Baixa } \\
\text { (<50 ha) }\end{array}$ \\
\hline 4 & $\begin{array}{l}\text { Ondulado } \\
\text { (8-20\%) }\end{array}$ & $\begin{array}{l}\text { Moderado } \\
(0,5 \text { a } 1 \mathrm{~m})\end{array}$ & Pastagens & $\begin{array}{l}\text { Moderada } \\
\text { (<10 ha) }\end{array}$ \\
\hline 8 & $\begin{array}{l}\text { Forte Ondulado } \\
\text { (20-45\%) }\end{array}$ & $\begin{array}{c}\text { Raso } \\
(0,25 \text { a } 0,5 \mathrm{~m})\end{array}$ & Culturas Anuais & $\begin{array}{l}\text { Densa } \\
(<5 \text { ha })\end{array}$ \\
\hline 16 & $\begin{array}{c}\text { Montanhoso } \\
\text { (45-75\%) }\end{array}$ & $\begin{array}{l}\text { Muito Raso } \\
(<0,25 \mathrm{~m})\end{array}$ & - & $\begin{array}{l}\text { Muito Densa } \\
\text { (<2,5 ha) }\end{array}$ \\
\hline
\end{tabular}

De acordo com a distribuição percentual de ocorrência das classes para os diferentes atributos da terra foi feita uma ponderação para estabelecer o índice representativo para cada um dos atributos da unidade geoambiental. A soma destes índices ponderados representa o índice de vulnerabilidade ambiental, conforme fórmula:

$$
\mathrm{IVA}=\mathrm{IRE}+\mathrm{ISO}+\mathrm{IUT}+\mathrm{IDP}
$$

Em que o IVAé o Índice de vulnerabilidade ambiental; o IRE, Índice de relevo; o ISSO, Índice de solo; o IUT, Índice de uso da terra; e o IDP,o Índice de densidade populacional.

Considerando os índices atribuídos as características dos diferentes fatores são possíveis estabelecer as seguintes classes de vulnerabilidade: Muito Baixa (04-06), Baixa (06-12), Média (12-24), Alta (24-40) e Muito Alta (40-56). Considerando que, nos resultados do trabalho os dados apresentaram uma concentração na classe média de vulnerabilidade, esta foi subdividida em média baixa (12-16), média (16-20) e média alta (20-24), para melhor diferenciar as diversas unidades geoambientais da bacia hidrográfica do açude Camará.

\section{RESULTADOS E DISCUSSÃO}

$\mathrm{Na}$ intenção de atender as necessidades locais de planejamento, a área da bacia hidrográfica da barragem Camará foi subdividida de acordo com as formas de relevo, uso da terra (sistemas de produção) e tipo de solo (Figura 2), os quais integrados formam as Unidades Geoambientais (Ugeas). O mapeamento de uso da terra realizado na classificação digital da imagem foi um apoio de campo bastante importante na divisão destas unidades de paisagem.

$\mathrm{Na}$ área da bacia hidrográfica Camará foi identificado 19 Unidades Geoambientais (Figura 3)), separadas de acordo com o tipo de solo, unidades fitogeográficas, rede de drenagem, uso do 
solo, relevo e outros fatores, no total de aproximadamente $104 \mathrm{~km} 2$, na tabela 1 , observa-se que a unidade do Topo de Esperança, apresenta-se com a maior área, 1278.1 ha, enquanto que a menor área mapeada foi à unidade de paisagem Lagoa Verde com 170.4 ha.

Tabela 1 - Mapeamento das unidades de paisagem com suas áreas e respectivas porcentagens na Bacia Hidrográfica do açude Camará

\begin{tabular}{|l|c|c|}
\hline \multicolumn{1}{|c|}{ Unidades Geoambientais } & \multicolumn{2}{c|}{ Área pertencente à BHC } \\
\cline { 2 - 2 } & ha & \% \\
\hline 1. Cepilho & 481.5 & 4,6 \\
\hline 2. Caiana & 284.5 & 2,7 \\
3. Topo de Remígio & 591.0 & 5,7 \\
\hline 4. Vertentes Remígio & 963.3 & 9,3 \\
5. Pastagens do Riacho do Boi & 620.2 & 6,0 \\
\hline 6. Mulatinha & 290.9 & 2,8 \\
7. Lagoa Verde & 170.4 & 1,6 \\
\hline 8. Topo de Esperança & 1278.1 & 12,4 \\
9. Riachão & 486.0 & 4,7 \\
\hline 10. Caldeirão-Camará & 350.8 & 3,4 \\
11. Sítios das Bananeiras & 1134.8 & 11,1 \\
\hline 12. Pastagens de Alagoa Nova & 811.3 & 7,8 \\
13. Pastagens de São Tomé & 496.6 & 4,8 \\
\hline 14. São Tomé & 316.9 & 3,0 \\
15. Encosta de São Tomé & 367.8 & 3,5 \\
\hline 16. Mumbuca & 316.3 & 3,1 \\
17. Quebra-Pé & 274.4 & 2,6 \\
\hline 18. Riacho Amarelo & 650.1 & 6,3 \\
19. Camucá-Santarém & 475.1 & 4,6 \\
\hline Total & 10360 & 100 \\
\hline
\end{tabular}

\section{Características Físicas das Ugeas}

a) Unidade Geoambiental Cepilho e de Caiana

É o ponto mais elevado da área, local das nascentes dos riachos Cepilho e Bonfim, seus principais sistemas de drenagem. O clima é úmido, típico da região Brejeira, área onde predominava o plantio de cana-de-açúcar, dos antigos engenhos. A Unidade caracteriza-se por apresentar um relevo ondulado a forte ondulado, onde predomina pequenas a médias propriedades, cuja principal estratégia de produção agrícola, na atualidade, é a agropecuária de corte e leite.

Os solos predominantes são os ARGISSOLO VERMELHO AMARELO, relevo forte ondulado, moderadamente profundos a profundos, drenagem moderada de baixa a média fertilidade. Nas várzeas das drenagens ocorrem os NEOSSOLOS FLÚVICOS, muitas vezes Gleico (Hidromórficos), onde se localiza as reservas hídricas das propriedades. Nestes solos são comuns os cultivos de forrageiras, fruteiros diversos, culturas alimentares e pequenas hortaliças.

A Unidade de Caiana com relevo forte ondulado destaca-se na paisagem pela presença de plantios de citrus e banana nas posições das linhas de topo, particularmente na comunidade Caiana de Cima, com solos bem estruturados profundos (ARGISSOLO VERMELHO AMARELO eutrófico $\mathrm{Tb}$, com A moderado, textura argilosa, fase floresta subcaducifólia, relevo forte ondulado). Na comunidade de Caiana de Baixo, a noroeste da unidade, em posição mais rebaixada, ocorre os solos NEOSSOLOS REGOLÍTICOS profundos nas posições de topo e terço superior de encosta, 


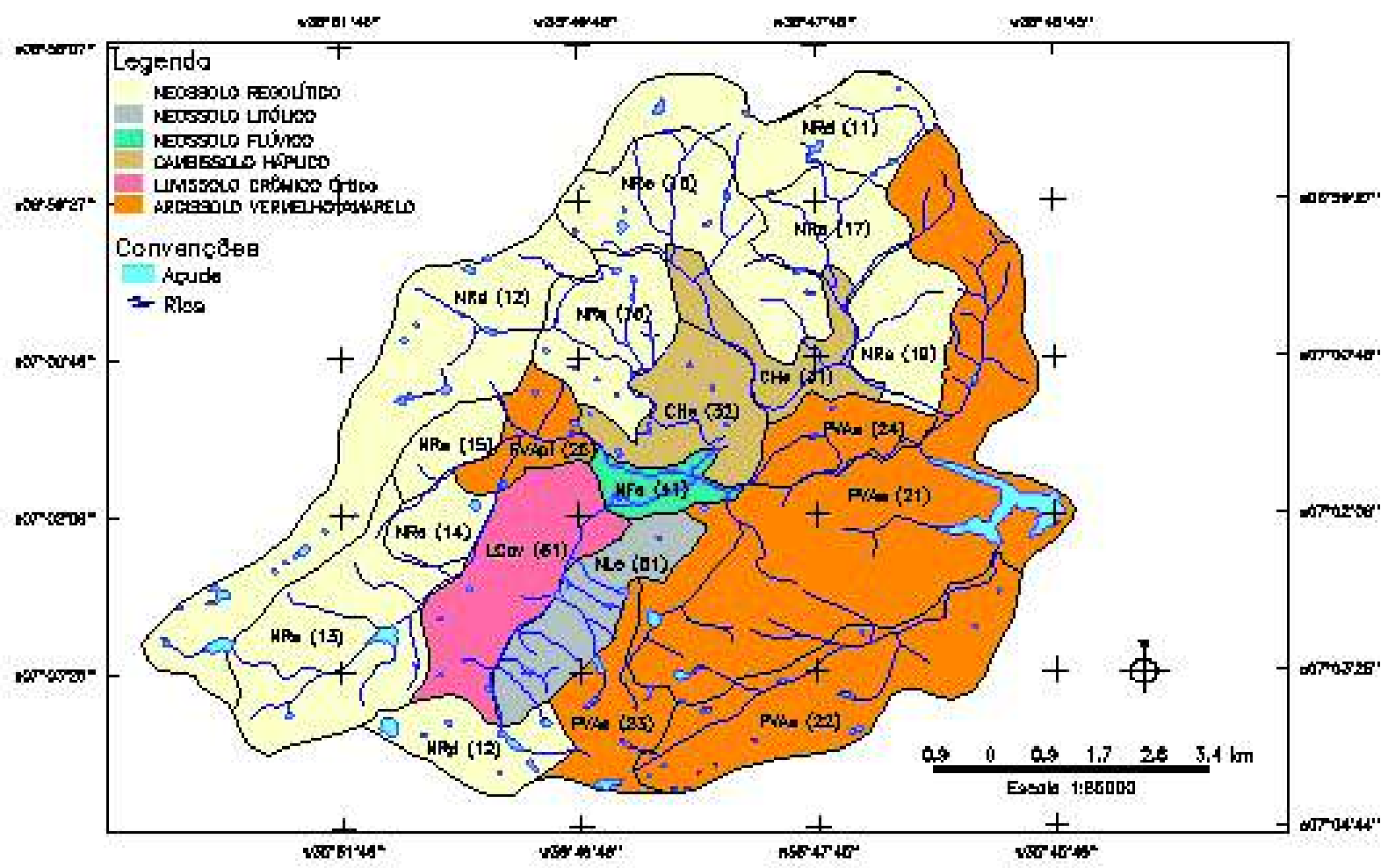

Figura 2 - Mapa de solos da bacia hidrográfica do açude Camará/PB

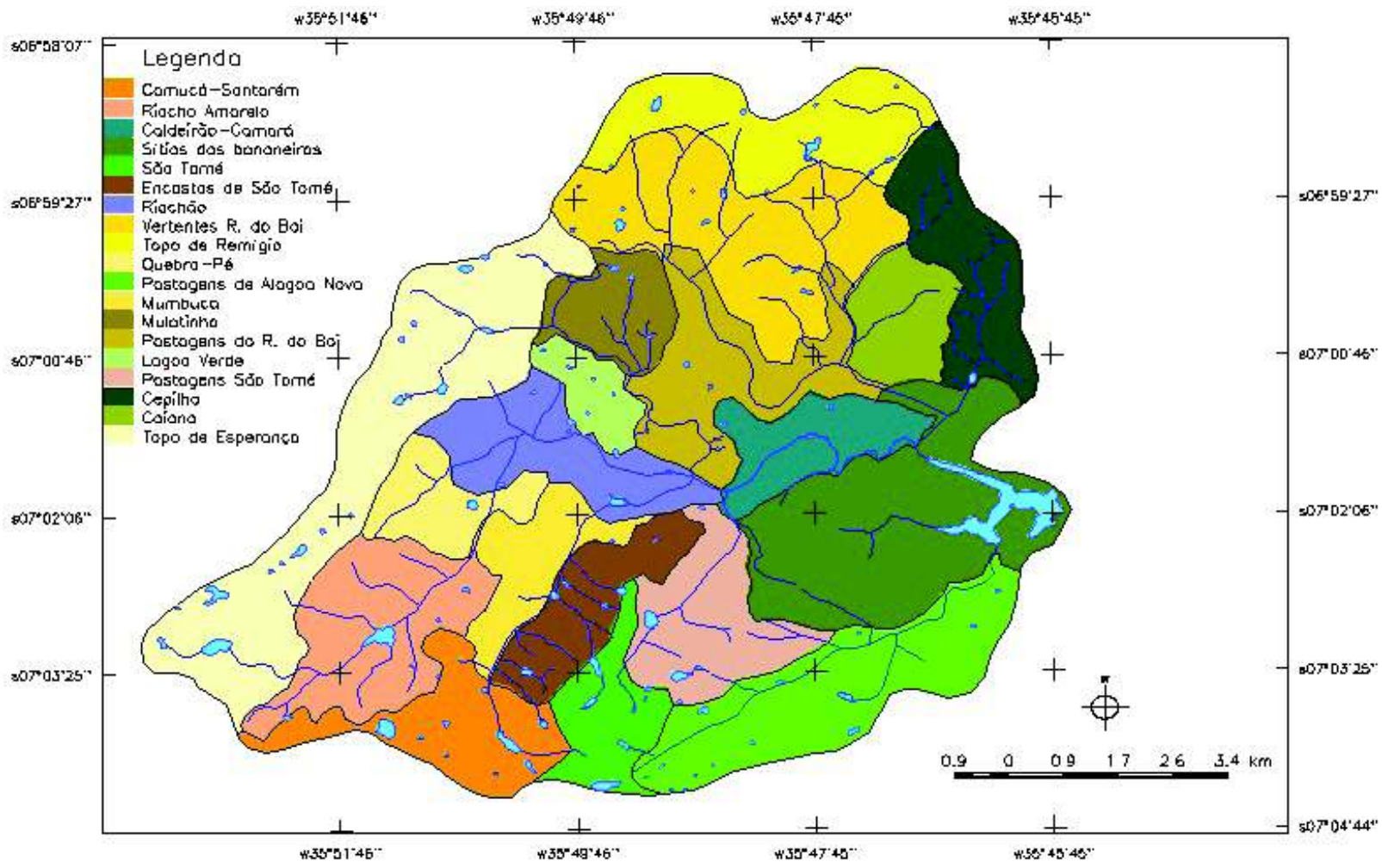

Figura 3 - Mapa unidades geoambientais da bacia hidrográfica do açude Camará/PB 
propiciando o uso intensivo da terra.

Em toda a Unidade, nas encostas, à medida que a declividade vai aumentando os solos de topo vão ficando menos profundos e desenvolvidos, passando a ocorrer os solos CAMBISSOLO e NEOSSOLO LITÓLICO, eutróficos, com A moderado, textura média, com freqüência podendo ocorrer pedregosidade e afloramento de rochas, gnaisse e granito. Cortando transversalmente de nordeste para sudoeste o riacho Caiana é o principal dreno desta Unidade Geoambiental, desaguando no riacho Jenipapo, próximo a foz com o riacho do Boi, no limite desta unidade. Este riacho separa as duas Comunidades Caiana de Baixo e de Cima.

b) Unidade Geoambiental Topo de Remígio e de Vertentes do Riacho do Boi

Compreende a área próxima à cidade de Remígio ao longo do divisor da bacia, com altitude superior a 600 metros. O solo predominante é o NEOSSOLO REGOLÍTICO distrófico, profundo, relevo suave ondulado a ondulado, fase floresta sub-caducifólia. Em menor proporção, nas áreas mais planas e em cabeceiras de drenagem ocorrem o NEOSSOLO QUARTZARÊNICO de várzea, glêico (hidromórfico) ou não, textura indiscriminada.

A maior disponibilidade hídrica devido à profundidade dos solos e possivelmente pelo aumento da precipitação devido à posição elevada do relevo, em contraposição as massas úmidas do interior da bacia hidrográfica, possibilitam nesta unidade geoambiental, o estabelecimento de uma grande diversidade de cultivos. Gravatá-Açú de Cima é a comunidade mais densamente povoada desta Ugea, contando com a concentração do posto de saúde, telefônico e da sede da Associação.

As terras desta Ugea (vertentes do Riacho do Boi) formam as cabeceiras do riacho do Boi e grande parte da drenagem do riacho Jenipapo, as quais pertencem quase que totalmente ao município de Remígio. As áreas agrícolas com declives suaves ondulados estendem-se em faixas de largura irregular ao longo dos divisores da drenagem, sendo formadas predominantemente, por solos NEOSSOLOS REGOLÍTICOS eutróficos e distróficos, arenosos e profundos.

Nas terras íngremes que formam as encostas dos vales profundos em forma de $\mathrm{V}$, ocorrem solos rasos, NEOSSOLOS LITÓLICOS Eutróficos com A fraco, textura arenosa e/ou média, associados à CAMBISSOLOS HÁPLICOS Tb Eutróficos e ARGISSOLOS VERMELHO-AMARELO Eutróficos $\mathrm{Tb}$, plíntico, com A moderado, textura argilosa, este último mais freqüente na comunidade Mata Redonda. $\mathrm{O}$ comum nesta unidade geoambiental são as áreas de encostas pertencerem às fazendas de criação de gado, servindo de áreas de pastagens.

c) Unidade Geoambiental Pastagens do Riacho do Boi e Mulatinha

Esta unidade é formada pelas terras das encostas íngrimes e secas da depressão profunda que forma o riacho do Boi. Em toda a área devido ao forte declive e aos cultivos antecedentes inadequados, hoje substituídos por pastagens, apresentam sinais evidentes de avançados processos de erosão. De alguma forma as terras dessa unidade geoambiental são formadas pelos terços inferiores das unidades de relevo das unidades geoambientais circunvizinhas.

Os solos predominantes são os CAMBISSOLOS HÁPLICOS Tb Eutróficos, com A moderado e horizonte B variegado, moderadamente profundo e NEOSSOLOS LITÓLICOS Eutróficos com A fraco, textura arenosa e média, relevo ondulado e forte ondulado. A vegetação natural é do tipo Floresta Caducifólia, denotando um regime hídrico de menor disponibilidade de água devido aos seus solos rasos e declivosos.

A unidade de Mulatinha localiza-se imediatamente abaixo do unidade Topo de Esperança, da qual apresenta um desnível abrupto de mais de 50 metros, formam uma unidade de paisagem de relevo suavizado, com vales na forma de $\mathrm{V}$ aberto, que as diferenciam das unidades circunvizinhas. Os solos predominantes são NEOSSOLOS REGOLÍTICOS Eutróficos, arenosos, profundos nas 
áreas de relevo mais planos e moderadamente profundo nos terços médios das encostas.

Nas áreas de nascentes, no terço inferior das encostas, ocorrem o NEOSSOLO QUARTZARÊNICO, hidromórfico, resultante dos depósitos coluvionais dos solos arenosos de montante. No contato com a linha do platô da Unidade de Esperança, em terrenos mais declivosos, ocorrem em menor proporção solos pouco desenvolvidos, CAMBISSOLOS, ARGISSOLOS e NEOSSOLOS LÍTICOS, com A fraco, textura arenosa, normalmente fortemente erodidos, apresentando afloramentos de rochas.

\section{d) Unidade Geoambiental Lagoa Verde e Topo de Esperança}

Esta é a menor unidade individualizada na bacia hidrográfica. Ocupa uma área de 170,4 ha encravada no centro da área de estudo. Esta unidade destaca-se na paisagem pelo uso diferenciado das suas terras, onde um grande número de pequenas propriedades cultivam pomares de citrus e de fruteiras diversas, além do cultivo de culturas alimentares tradicionais (feijão, milho, mandioca e macaxeira).

Os solos predominantes são o NEOSSOLOS REGOLÍTICOS Eutróficos, arenosos, profundos, relevo suave ondulado, e ARGISSOLO VERMELHO AMARELO eutrófico, Tb, com A moderado, textura argilosa, fase floresta subcaducifólia, relevo ondulado. A maior profundidade e disponibilidade de nutrientes dos solos, além do empreendedorismo da comunidade, em grande parte, devem explicar o estabelecimento desta agricultura diferenciada desta Unidade Geoambiental.

Localizada na posição de topo ao longo do divisor, de noroeste para oeste da bacia, A unidade geoambiental de Topo de Esperança é a maior das unidades geoambientais com 1278,1 ha, que corresponde a $12,4 \%$ da área de estudo. Compreende as terras com altitudes acima de 600 metros, com relevo suave ondulado onde predomina os NEOSSOLOS REGOLÍTICOS Distrófico, solos profundos textura arenosa. Nas áreas mais planas é comum a formação de lagoas associadas a afloramentos de rocha. Estes afloramentos surgem também nas rupturas do relevo nos limites para outras unidades geoambientais, ou dentro da unidade associados à erosão em áreas mais declivosas.

A baixa fertilidade dos solos praticamente obriga o uso anual da adubação orgânica, sendo uma tradição o cultivo em leirões. Este método de cultivo, tradicionalmente feito manualmente com enxada, ou mesmo atualmente com o uso do sulcador tração animal, permitem, na primeira fase de sua construção, na encama, a aplicação do esterco de gado. Este insumo é normalmente adquirido do Curimataú ou Cariri, regiões semi-áridas vizinhas, de criação extensiva de gado, que nem sempre é disponível em quantidade e qualidade suficientes aos interesses e ao bolso dos agricultores. É comum se observar a formação de sulcos em áreas relativamente planas, apesar da alta permeabilidade dos solos, precipitação mais baixa e menor disponibilidade de água dos solos arenosos.

\section{e) Unidade Geoambiental Riachão e Caldeirão-Camará}

A Unidade Riachão pode ser dividida em duas sub-unidades, uma a montante, formada por terrenos ondulados e pedregosos onde a drenagem, após o encontro dos riachos Amarelo e Quebra-Pé, sofre uma forte derivação para a direita e outra área a jusante, formada por terrenos planos aluvionais que se alargam com a contribuição dos sedimentos do riacho Santarém. Esta área de várzea compreende as terras da Fazenda Riachão que tem a criação de gado sua principal atividade, além de uma cerâmica que utiliza a argila da várzea para fabricação de tijolos.

A área a montante da Unidade Riachão encontra-se bastante vegetada com mata, bosques de Sabiá e capoeiras, sendo em grande parte utilizada com pastagens, onde predomina o solo ARGISSOLO VERMELHO AMARELO eutrófico Tb, com A moderado, textura argilosa, relevo ondulado. A noroeste da Unidade, no contato com o platô rochoso da Unidade de Esperança ocorrem os solos NEOSSOLOS REGOLÍTICOS Eutróficos, textura arenosa, profundo, relevo ondulado e 
NEOSSOLOS LITÓLICOS, A fraco, textura arenosa relevo ondulado a forte ondulado e AFLORAMENTOS DE ROCHA. Esta área é ocupada por pequenas propriedades agrícolas e os terrenos mais declivosos são utilizados com pastagens.

A unidade Caldeirão-Camará é a mais interior e baixa Unidade Geoambiental da bacia hidrográfica. Representa a cabeceira do divisor do sistema de drenagem do riacho do Boi-Jenipapo com o rio Camará. Apresenta relevo ondulado no seu interior, embora devido ao aprofundamento dos rios, seus limites no contato da drenagem apresentam desníveis acentuados. O solo predominante é o ARGISSOLO VERMELHO AMARELO Eutrófico Tb, com A proeminente, textura argilosa, fase floresta subperenifólia, relevo ondulado. A maior precipitação e o maior armazenamento de água nos solos mais profundos facilitam o estabelecimento das plantas frutícolas.

\section{f) Unidade Geoambiental Sítios das Bananeiras}

Caracteriza-se pela presença de pequenos sítios e do terreno montanhoso, onde a bananeira é a principal cultura das unidades produtivas. Os solos predominantes são o ARGISSOLO VERMELHO AMARELO eutrófico Tb e o ARGISSOLO VERMELHO AMARELO eutrófico $\mathrm{Tb}$, plíntico, ambos com A proeminente, textura argilosa, floresta subperenifólia, relevo ondulado e forte, ondulado; associados ao NEOSSOLO LITÓLICO eutrófico, com A proeminente, textura média, fase pedregosa e rochosa, relevo forte ondulado e montanhoso, substrato gnaisse e granito. O horizonte A destes solos são espessos, rico em matéria orgânica e bem estruturado, possibilitando um maior armazenamento de água, boa drenagem e melhores condições para o desenvolvimento do sistema radicular das plantas. Apesar disto são solos relativamente ácidos, e que, apesar de eutróficos (saturação de bases maior que 50\%) apresentam argilas com baixa capacidade de troca, baixos teores de fósforo e médios teores em potássio.

$\mathrm{Na}$ encosta noroeste da Unidade, voltada para o interior da bacia hidrográfica, principalmente nas comunidades de Vista Alegre e Ribeiro, o plantio de citrus vem substituindo o plantio da banana. Em todas estas unidades a erosão dos solos devido à maior declividade dos solos e a falta de medidas para o seu controle é um problema sempre presente. Particularmente nas áreas com culturas anuais de subsistência, praticada pelos agricultores menos capitalizados, onde o processo erosivo é acelerado, provocando à perda do horizonte A destes solos, seu maior capital. O resultado é a exposição do sub-horizontes argílicos, compactados, o surgimento de pedras e afloramento de rochas causando a diminuição da produtividade dos solos, a pobreza do agricultor e danos irreparáveis ao meio ambiente (solo, água e biodiversidade).

\section{g) Unidade Geoambiental Pastagens de Alagoa Nova e de São Tomé}

Corresponde as terras de relevo ondulado da margem direita do riacho do Pinga, englobando as terras de várzea e o terço inferior da margem esquerda, até o limite em que a declividade se acentua sobre o relevo montanhoso da linha de serra Gameleira-São Tomé, que formam as Unidades Geoambientais vizinhas, dentro da área de estudo.

Muitas das terras desta Unidade já foram áreas de produção de cana-de-açúcar de antigos engenhos, hoje transformados em fazendas de criação de gado. O solo predominante é o ARGISSOLO VERMELHO AMARELO eutrófico Tb, com A proeminente, textura argilosa, floresta subperenifólia, relevo ondulado; ocorrendo também em áreas de relevo mais acentuado, nas cabeceiras de drenagem o NEOSSOLO LITÓLICO eutrófico, com A proeminente/moderado, textura média, relevo ondulado substrato gnaisse e granito.

A Unidade Geoambiental de São Tomé caracteriza-se pela predominância do uso das terras com pastagem plantada (Brachiaria e Pangola), em relevo forte ondulado a montanhoso. A drenagem do riacho São Tomé e das vertentes da serra para o riacho do Pinga são em forma de "V", muito 
profundas, formando vales estreitos e encostas com declives muito acentuados. Na bacia do riacho São Tomé ocorre um maior número de pequenas propriedades, com pequenas áreas de fruticultura, contudo à medida que vai subindo a serra ocorre o predomínio de maiores áreas de pastagens.

Além do solo ARGISSOLO VERMELHO AMARELO eutrófico Tb, com A proeminente, textura argilosa, floresta subperenifólia, relevo forte ondulado a montanhoso e do NEOSSOLO LITÓLICO eutrófico, com A proeminente, textura média, fase pedregosa e rochosa, relevo forte ondulado e montanhoso, substrato gnaisse e granito; observa-se a ocorrência de CAMBISSOLOS HÁPLICOS, Tb Eutróficos, associados aos Argissolos nas áreas de relevo forte ondulado.

Em muitas áreas de relevo montanhoso e forte ondulado observa-se o efeito da compactação do solo pelo excesso de pisoteio, áreas onde já não nasce mais capim e os caminhos dos animais fazem banquetas no terreno. Em outras áreas a cor avermelhada da superfície do terreno denota a exposição dos subhorizontes argilosos dos solos Vermelhos Amarelos.

h) Unidade Geoambiental São Tomé e Unidade Geoambiental Encostas de São Tomé

A unidade de São Tomé (Figura 29) situa-se ao sul da Bacia Camará, no final da linha de serra que vem de Gameleira, formando um platô que é nascente de diversos cursos d'água locais, tais como, os riachos do Pinga, São Tomé, Santarém e alguns de seus afluentes. Éumaáreaainda considerada como sendo úmida, de floresta subperenifólia, estabelecida pelo favorecimento da boa capacidade de armazenamento de água dos seus solos argilosos e profundos.

O relevo é suave ondulado a ondulado e os solos predominantes é o ARGISSOLO VERMELHO AMARELO, Eutrófico Tb, com A proeminente e ARGISSOLO VERMELHO AMARELO, Eutrófico Tb, abruptico, com A moderado, textura argilosa e NEOSSOLO REGOLÍTICO distrófico, com A fraco, textura arenosa, relevo suave ondulado e ondulado. O distrito de São Tomé pertence ao município de Alagoa Nova. Situa-se numa linha de divisor que avança para o interior da bacia, colocando-se num ponto de visão privilegiada para a depressão da bacia hidrográfica.

A unidade Encostas de São Tomé é formada pela encosta com face noroeste da serra de São Tomé, portanto a sotavento da linha de serra Gameleira-São Tomé. Tal condição, oposta a direção predominante dos ventos na região, alísios de sudeste, provoca uma repentina queda da precipitação, evidenciada pela mudança do padrão de vegetação, de floresta subperenifólia para subcaducifólia.

Embora predomine áreas com pastagens é uma unidade geoambiental bastante habitada, o que, pelas condições de solos mais rasos e declivosos, as inúmeras áreas de cultivo espalhadas pela Unidade, tem provocado degradação severa a muito severa. Os solos observados no terço superior da encosta guardam relações com os Argissolos do topo, da Ugea São Tomé, com ocorrência de Argissolos plínticos e câmbicos. O solo predominante é o NEOSSOLO LITÓLICOS Eutróficos, com A fraco, textura média, relevo forte ondulado e montanhoso. No terço inferior da encosta, nas áreas de suavização do relevo, passa a ocorrer com maior freqüência, o solo LUVISSOLO CRÔMICO vértico, com A fraco, textura média, floresta caducifólia, que é predominante na Ugea vizinha de Mumbuca.

\section{i) Unidade Geoambiental Mumbuca e Unidade Geoambiental Quebra-Pé}

O relevo é ondulado e o solo predominante é o Luvissolo Crômico vértico (Bruno Não Cálcico vértico), com A fraco, textura média, fase pedregosa, floresta caducifólia. Nas áreas mais acidentadas das cabeceiras de drenagem ocorrem Solos Litólicos eutróficos, com A fraco, textura arenosa e/ou média, fase pedregosa e rochosa, floresta caducifólia, relevo ondulado, substrato gnaisse e granito.

A Unidade Geoambiental Quebra-Pé, apresenta forte desnível que expõe paredões de rochas graníticas e gnáissicas que afloram em diversos pontos da encosta. Esta unidade compreende as terras com relevo ondulado localizadas a margem esquerda do riacho Quebra-Pé, no sopé da encosta do 
Alto de Esperança, e as terras com relevo suave ondulado que se localizam no centro da unidade, entre os riachos Quebra-Pé e Amarelo e na margem direita do riacho Amarelo, em área contígua, já na comunidade Mumbuca, no município de Alagoa Nova.

Com exceção da área localizada na comunidade Mumbuca, com solos LUVISSOLO CRÔMICO VÉRTICO nas demais áreas ocorrem os NEOSSOLOS REGOLÍTICOS eutróficos, A fraco, floresta subcaducifólia em relevo suave ondulado no centro da Ugea e em relevo ondulado a margem esquerda do riacho Quebra-Pé. Esta Ugea é uma área essencialmente agrícola, O gado na corda é também utilizado para o aproveitamento dos resíduos dos roçados pela maioria dos agricultores. Em áreas mais declivosas observa-se áreas de pastagens. É uma comunidade bastante organizada, dispondo de associação comunitária com sede social e grupo escolar.

\section{j) Unidade Geoambiental Riacho Amarelo e Camucá-Santarém}

Compreendem uma extensa área de capoeiras e pastagens degradadas. São propriedades que em grande parte foram formadas pela incorporação de pequenas áreas agrícolas degradadas por cultivos intensivos dos solos. Os solos predominantes nas encostas da margem esquerda do riacho Amarelo são os NEOSSOLO REGOLÍTICO eutrófico, A fraco, textura arenosa, relevo ondulado e solos NEOSSOLO LITÓLICO eutrófico, A fraco, textura arenosa, relevo ondulado a forte ondulado. Na margem direita predomina o NEOSSOLO LITÓLICO eutrófico A fraco, textura arenosa, relevo ondulado a forte ondulado e LUVISSOLO CRÔMICO Órtico vértico, A fraco, textura média, relevo ondulado. Enquanto que, nas áreas de várzeas ocorrem os NEOSSOLO FLÚVICO, textura indiscriminada, relevo plano.

Na Camucá-Santarém, os solos predominantes são, na área de topo mais aplainadas o NEOSSOLO REGOLÍTICO distrófico, A fraco, textura arenosa, fase floresta subcaducifólia, relevo suave ondulado a ondulado; nas áreas de transição para as Ugeas Riacho Amarelo e Mumbuca, associação de NEOSSOLO LITÓLICO eutrófico, A fraco, textura arenosa e/ou média, fase pedregosa, floresta caducifólia, relevo ondulado e LUVISSOLO CRÔMICO Órtico vértico, A fraco, textura média, floresta caducifólia, relevo ondulado.

\section{Vulnerabilidade Ambiental das Ugeas}

A partir das informações de solo, relevo, uso da terra e densidade populacional (tamanho das propriedades em ha), foi desenvolvida uma proposta metodológica para determinar o índice de vulnerabilidade ambiental (IVA) da bacia hidrográfica Camará (Tabela 2 e Figura 4).

Na Tabela 2, observou-se que a Ugea Encosta São Tomé, abrangendo 3,5\% da bacia apresentou uma vulnerabilidade alta de acordo com a classe de IVA, fato que ocorreu provavelmente devido a $90 \%$ da área apresentar relevo forte ondulado a montanhoso e $80 \%$ do solo ser raso a muito raso, analisando-se as características das associações de solos presentes nesta Ugea.

As Ugeas Cepilho, Vertentes de Remígio e Mumbuca representam juntas as áreas com índice de vulnerabilidade ambiental média alta, ou seja, 16,6\% da bacia. Índice determinado principalmente, devido ao relevo e solo, característicos destas unidades. Notando-se que, estes fatores naturais determinam à maior ou menor vulnerabilidade da área, enquanto que, os fatores antrópicos - uso da terra e densidade populacional, não apresentaram nesta bacia hidrográfica significância ao analisar a vulnerabilidade. Porém, é imprescindível citar a ausência de técnicas de conservação, onde os moradores cultivam morro abaixo, prática que só agrava a erosão, aumentando assoreamento dos 
afluentes dos rios.

Tabela 2 - Índice de Vulnerabilidade Ambiental da bacia hidrográfica Camará-PB

\begin{tabular}{|l|c|c|c|c|c|c|}
\hline \multicolumn{1}{|c|}{ Unidades Geoambientais } & Relevo & Solo & Uso & Pop. & Índice & Classe \\
IVA
\end{tabular}

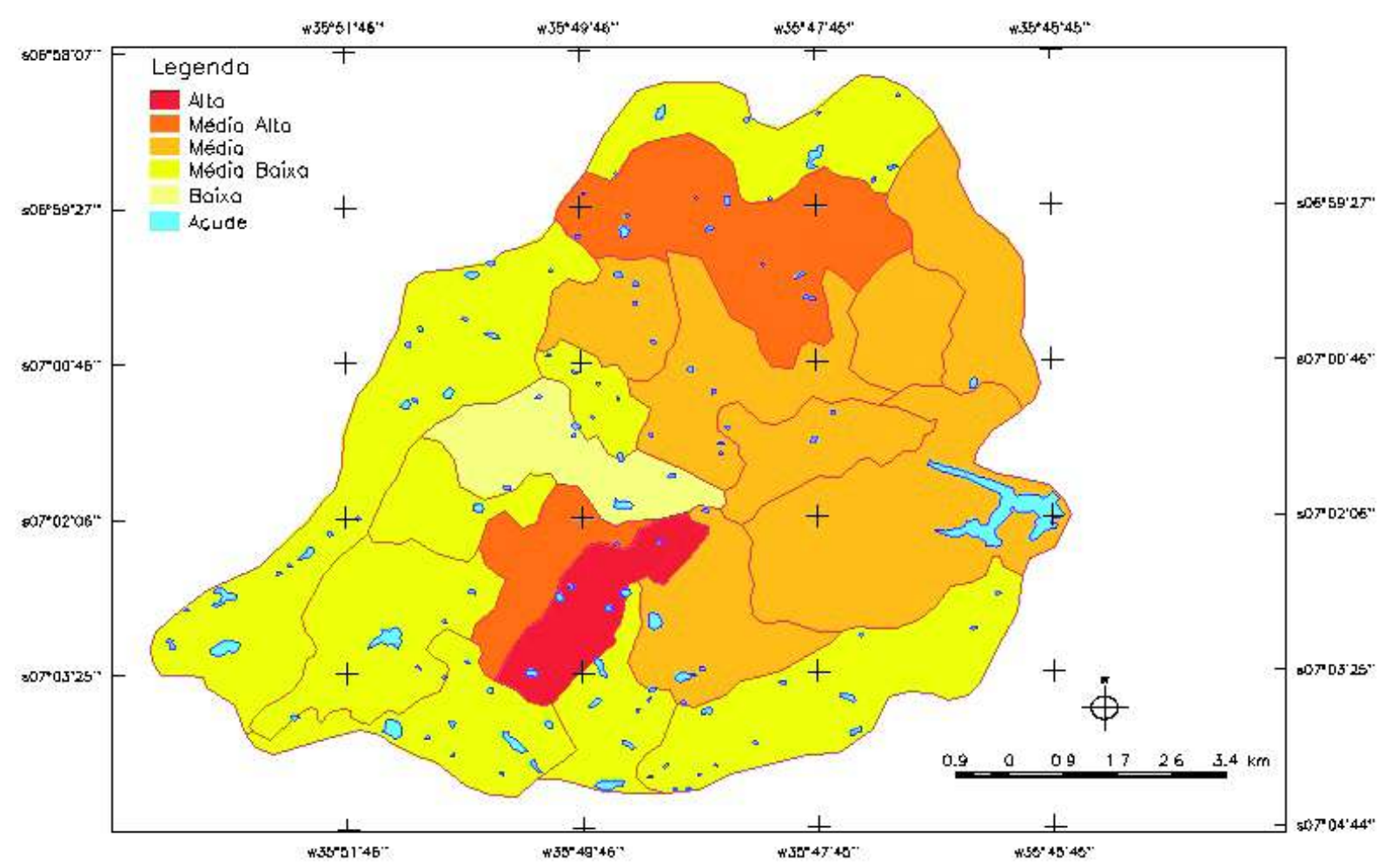

Figura 4 - Mapa de vulnerabilidade da bacia hidrográfica do açude Camará/PB 


\section{CONSIDERAÇÕES FINAIS}

A diversidade de paisagens da bacia hidrográfica da barragem Camará, principalmente no que se refere às formas de relevo, de solos e de sistemas de produção, apontou a importância do zoneamento geoambiental. Essa importância reside nas preocupações com a conservação do meio ambiente e com o desenvolvimento sócio-econômico e a preservação dos recursos naturais na área em busca do desenvolvimento sustentável.

Sobre a vulnerabilidade ambiental da Bacia, é média em 30,6\%, média baixa em 44,6\% e baixa em 4,7\% da área total da bacia hidrográfica em estudo, provavelmente devido aos solos profundos dos Regossolos de relevo suave ondulado e os Argissolos que apresentam profundidade efetiva que vaiam de moderado a profundo devido ao A moderado e A proeminente, apesar de estes solos ocorrerem onde o relevo ondulado a forte ondulado na área mais úmida da bacia. Dessa forma concluímos que:

- A base de dados georreferenciada e as informações temáticas obtidas neste trabalho deverá ser uma contribuição efetiva para articulação de propostas de ações para o desenvolvimento sustentado e preservação dos recursos naturais;

- Das unidades geoambientais identificadas, a agricultura é predominante no Topo de Esperança, Topo de Remígio, Camucá-Santarém, Mulatinha e Lagoa Verde áreas que predominam os solos REGOSSOLOS e relevo suave ondulado; as áreas de fruticultura embora não mapeadas predominam em área úmidas de relevo ondulado a forte ondulado;

- As unidades geoambientais que apresentaram maior vulnerabilidade são as Ugeas Encosta São Tomé, devido à forte declividade e solos rasos; Mumbuca devido a solos rasos e uso agrícola e Vertente Remígio devido à declividade, solos rasos e densidade populacional.

\section{REFERÊNCIAS BIBLIOGRÁFICA}

ALVES, H. M. R.; VIEIRA, T. G. C.; ANDRADE, H. Sistemas de Informação Geográfica na avaliação de impactos ambientais provenientes de atividades agropecuárias. - v. 21, no 202, p. 99-109 - Belo Horizonte: Revista Agropecuária e Ambiente / Informe Agropecuário, jan./fev., 2000.

BRASIL. Levantamento Exploratório - Reconhecimento de Solos do estado da Paraíba. Boletim 15. Rio de Janeiro: Convênio de Mapeamento de Solos MA / EPE - SUDENE / DRN / CONTAP / USAID / BRASIL, 1972. 650p.

CÂMARA, G., SOUZA, R.C.M., FREITAS, U.M., GARRIDO, J. SPRING: Integrating remote sensing and GIS by object-oriented data modelling. Computers \& Graphics, 20: (3) 395-403, May-June, 1996.

CÂMARA, G. \& MEDEIROS, J. S. Geoprocessamento para projetos ambientais. São José dos Campos: INPE, 1996. 39p. (Relatório do INPE).

CARVALHO JUNIOR, W.; CHAGAS, C. S.; PEREIRA, N. R.; STRACH, J. C. M. Elaboração de Zoneamentos agropedoclimáticos por geoprocessamento: soja em municípios do Rio Grande do Sul. Rev. Bras. Ciênc. Solo, vol. 27, nº 2. Viçosa: Mar./Apr., 2003.

DUARTE, S. M. A. Diagnóstico Ambiental e Planejamento da Microbacia Hidrográfica Timbaúba no Brejo Paraibano, através de Técnicas de Fotointerpretação e sistema de Informações Geográficas. Areia - PB: PPGMSA/UFPB, 2003.

ELC. Zoneamento agropecuário do estado da Paraíba. Paraíba: UFPB/FUNAPE/CCT/CCA/ELC, 1978. EMBRAPA. Procedimentos normativos de levantamentos pedológicos. Brasília: EMBRAPA - SPI, 1995. 101p.

EMBRAPA. Sistema Brasileiro de Classificação do Solo. Brasília: Embrapa Produção de informação. Rio de Janeiro: EMBRAPA Solos, 1999. 412p.

FARIA FILHO, A. F.; ARAÚJO, Q. R. Zoneamento do meio físico do município de Ilhéus, Bahia, Brasil,

Mercator - volume 9, número 20, 2010: set./dez. 
utilizando a técnica de geoprocessamento. Ilhéus, BA: CEPLAC/CEPEC, Boletim Técnico nº 187, 2003. 20p. FREITAS, S. R.; MELLO, M.C. S.; CRUZ, C. B. M. Relações entre maturidade estrutural da floresta e índices de vegetação na Mata Atlântica. Anais XII Simpósio Brasileiro de Sensoriamento Remoto, Goiânia, Brasil, 16-21 abril 2005, INPE, p. 1537-1544.

LACERDA, A. V. A semi-aridez e a gestão em Bacias Hidrográficas: visões e trilhas de um divisor de idéias. João Pessoa: Editora Universitária, 2003. 164p.

LIMA, V. Avaliação das terras da sub-bacia hidrográfica do Riacho do Cunha nos municípios de Areia e Remígio, estado da Paraíba. (Dissertação de mestrado) Areia: PPGMSA/CCA/UFPB, 2003. 51p.

LEPSCH, I. F. Manual para levantamento utilitário do meio físico e classificação de terras no sistema de capacidade de uso. 4a Aprox. Soc. Bra. Ci. Solo, Campinas-SP. 1991. 175p.

MOLENAAR, M. An introduction into the theory of topologic and hierarchical object modeling in geo-information systems. Wageningen: Wageningen Agricultural University-Center for Geo-Information Processing, 1996. 135p.

NOVO, Evelyn M. L. de Moraes. Sensoriamento Remoto: Princípios e Aplicações. São Paulo: Editora Edgard Blücher Ltda, 1988. 308p.

OSTENSEN, O. Mapping the future of geomatics. Paris, Prentice Hall International: ISO/TC 211, 1995. 49 P. (Bulletin, 1).

PEDRA, C. S.; CATELANI, C. S.; RESENDE, S. R. S.; BATISTA, G. T. Levantamento do meio físico de uma microbacia no município de Natividade da Serra, SP, através de técnicas de geoprocessamento e sensoriamento remoto, para suporte ao Programa Estadual de Microbacias Hidrográficas (PEMBH). Anais XII Simpósio Brasileiro de Sensoriamento Remoto, Goiânia, Brasil, 16-21 abril 2005, INPE, p. 3887-3889. PINTO, L. V. A.; FERREIRA, E.; BOTELHO, S. A.; DAVIDE, A. C. Caracterização física da bacia hidrográfica do Ribeirão Santa Cruz, Lavras, MG e uso conflitante da terra em suas áreas de preservação permanente. Cerne, Lavras, v. 11, n. 1, p. 49-60, jan./mar. 2005.

RAMALHO FILHO, A. BEEK, K. J. Sistema de Avaliação da aptidão agrícola das terras. $-3^{\mathrm{a}}$ ed. rev. - Rio de Janeiro: EMBRAPA-CNPS, 1994. 65p.

ROCHA, J. S. M. da. Manual de Projetos Ambientais. Santa Maria: Imprensa Universitária/UFSM, 1997. $423 p$.

ROCHA, J. V. El Sistema de Informaciones Geográficas (SIG) en los contextos de planificación del medio físico y de las cuencas hidrográficas. II Curso Internacional de Aspectos Geológicos de Protección Ambiental. Site acessado: <www.unesco.gov>. Dia de acesso: 01 out. 2005. (Capítulo 9, 102-113p.)

RODRIGUEZ, J. M. M.; SILVA, E. V.; CAVALCANTI, A. P. B. Geoecologia das paisagens: uma visão geossistêmica da análise ambiental. Fortaleza: Editora UFC, 2004. 222p.

SCHÄFER, A.; PEREIRA, R.; AGRA, G. Uso do Sensoriamento Remoto e Sistema de Informação Geográfica (SIG) no monitoramento da polícia ambiental do Rio Grande do Sul: Curso de Capacitação. $4^{a}$ Jornada de Educação em Sensoriamento Remoto no Âmbito do Mercosul. São Leopoldo, RS: 11 a 13 de agosto de 2004.

SILVA, A. B.; BRITES, R. S.; SOUSA, A. R. Caracterização do meio físico da microbacia Quatro Bocas, em Angelim, PE, e sua quantificação por Sistema de Informação Geográfica. Brasília: Pesq. Agropec. Bras. V. 34, no 1, p. 109-117, jan. 1999.

TRANCOSO, R.; CARNEIRO FILHO, A.; FERREIRA, D. A. C.; NOGUERA, S. P. Sistemas de Informação Geográfica como ferramenta para o diagnóstico e gestão de macrobacias no arco do desmatamento na Amazônia. Anais XII Simpósio Brasileiro de Sensoriamento Remoto, Goiânia, Brasil, 16-21 abril 2005, INPE, p. 2405-2412.

Trabalho enviado em setembro de 2010

Trabalho aceito em dezembro de 2010 